\title{
Multiferroic Cobalt Ferrite-Lead Iron Tungstate Composites
}

\author{
J. KulawiK*, D. SzWagierczak and P. GuzdeK \\ Institute of Electron Technology, Kraków Division, Zabłocie 39, 30-701 Kraków, Poland
}

\begin{abstract}
The paper presents dielectric, magnetic and magnetoelectric properties of multiferroic bulk composites based on $\mathrm{CoFe}_{2} \mathrm{O}_{4}$ ferrite and $\mathrm{Pb}\left(\mathrm{Fe}_{2 / 3} \mathrm{~W}_{1 / 3}\right) \mathrm{O}_{3}$ relaxor. X-ray diffraction analysis and scanning electron microscopy observations of ceramic samples revealed two-phase composition and fine grained microstructure with uniformly distributed ferromagnetic and ferroelectric phases. Dielectric permittivity measured in a temperature range $218-773 \mathrm{~K}$ at frequencies of $10 \mathrm{~Hz}-2 \mathrm{MHz}$ exhibits high and broad maxima attributed to dielectric relaxation. The hysteresis determined in a temperature range 4-393 K for magnetic field changing from $-80 \mathrm{kOe}$ to $80 \mathrm{kOe}$ is typical of hard magnetic materials. Saturation magnetizations and coercivities were found to decrease with increasing temperature. The courses of zero field cooled and field cooled magnetization versus temperature curves measured in the temperature range 4-393 K imply spin glass behavior of the ferrite and antiferromagnetic transition of the relaxor at low temperatures. The ferrite-relaxor composite shows high magnetoelectric voltage coefficient which distinctly increases with increasing frequency of ac magnetic field and is slightly higher for higher ac and dc magnetic fields.
\end{abstract}

PACS: 75.50.-y, 75.60.Ej, 75.85.+t, 77.22.Ch

\section{Introduction}

Multiferroic materials in which applied magnetic field causes dielectric polarization or external electric field results in induced magnetization have recently attracted great attention due to their potential applications comprising magnetic field sensors, memory devices, transducers, filters, waveguides, switches, phase invertors etc. Since single phase multiferroics are rare and show some disadvantages, like low electrical resistivity or low magnetic transition temperatures, ferroelectric-ferromagnetic composites are often used to attain strong magnetoelectric effect as a "product property" of the material. The most popular compositions are those containing cobalt or nickel ferrite as a ferromagnetic phase and piezoelectric $\mathrm{BaTiO}_{3}$ or $\mathrm{Pb}(\mathrm{ZrTi}) \mathrm{O}_{3}$ as a ferroelectric phase [1-5].

This paper focuses on the studies of microstructure, dielectric, magnetic and magnetoelectric properties of bulk composites based on ferrite $\mathrm{CoFe}_{2} \mathrm{O}_{4}(\mathrm{CF})$ and solid state solution of relaxor ferroelectric $\mathrm{Pb}\left(\mathrm{Fe}_{2 / 3} \mathrm{~W}_{1 / 3}\right) \mathrm{O}_{3}(\mathrm{PFW})$ and normal ferroelectric $\mathrm{PbTiO}_{3}(\mathrm{PT})$. $\mathrm{CoFe}_{2} \mathrm{O}_{4}$ is a hard magnetic material with the Curie temperature around $790 \mathrm{~K}$, high coercivity, good chemical stability and large magnetostriction $[6,7] . \quad \mathrm{Pb}\left(\mathrm{Fe}_{2 / 3} \mathrm{~W}_{1 / 3}\right) \mathrm{O}_{3}$ is a ferroelectric relaxor, sinterable at relatively low temperatures below $1173 \mathrm{~K}$, which shows high dielectric constant and belongs to a narrow group of natural single phase multiferroics [8-10]. The diffuse relaxor transition of PFW is reported to be around $150 \mathrm{~K}$ and the antiferromagnetic transition to be at $350-380 \mathrm{~K}[8]$.

\footnotetext{
${ }^{*}$ corresponding author; e-mail: jkulawik@ite.waw.pl
}

\section{Experimental}

$\mathrm{CoFe}_{2} \mathrm{O}_{4}$ was synthesized by a solid state reaction at $1323 \mathrm{~K}$ for $5 \mathrm{~h}$. $\mathrm{Pb}\left(\mathrm{Fe}_{2 / 3} \mathrm{~W}_{1 / 3}\right) \mathrm{O}_{3}$ was obtained by a two-step process comprising calcination of $\mathrm{Fe}_{2} \mathrm{O}_{3}$ and $\mathrm{WO}_{3}$ at $1273 \mathrm{~K}$ for $5 \mathrm{~h}$, and then calcination of $\mathrm{Fe}_{2} \mathrm{WO}_{6}$ and $\mathrm{PbO}$ at $1073 \mathrm{~K}$ for $5 \mathrm{~h}$. The mixture with the composition $0.5 \mathrm{CoFe}_{2} \mathrm{O}_{4}-0.375 \mathrm{~Pb}\left(\mathrm{Fe}_{2 / 3} \mathrm{~W}_{1 / 3}\right) \mathrm{O}_{3}-0.125 \mathrm{PbTiO}_{3}$ was ball milled, pressed into pellets and subsequently sintered at $1173 \mathrm{~K}$ for $2 \mathrm{~h}$. Phase composition of the samples was studied by an X'Pert Philips diffractometer. Dielectric properties were determined in a temperature range 218-773 K at frequencies of $10 \mathrm{~Hz}-2 \mathrm{MHz}$, using a LCR QuadTech meter. Microstructure and chemical composition of the ceramics were investigated using a FEI scanning microscope and EDAX Genesis EDS system.

Magnetic properties of the ceramic composites were measured using a vibrating sample magnetometer (PPMS Ever Cool, 9 tesla, Quantum Design) in a temperature range 4-393 K. Hysteresis loops were determined at magnetic field ranging from -80 to $80 \mathrm{kOe}$. Zero field cooled and field cooled magnetization curves at magnetic field of 100 Oe were also studied. Magnetoelectric effect measurements were carried out at room temperature using a laboratory stand (AGH University of Science and Technology). Samples were placed in external dc magnetic field created by an electromagnet and in ac sinusoidal magnetic field produced by the Helmholtz coils. A voltage generated due to magnetoelectric effect between the sample surfaces was measured using a high impedance lock-in amplifier. Magnetoelectric coefficients were determined for various magnitudes of the dc magnetic field $(0.3-7.2 \mathrm{kOe})$ and frequencies of the ac mod- 
ulation field $(10 \mathrm{~Hz}-10 \mathrm{kHz})$.

\section{Results and discussion}

The X-ray diffraction analysis of the ceramic samples showed their two-phase composition with no additional phases, besides PFW and $\mathrm{CoFe}_{2} \mathrm{O}_{4}$. As illustrated in Fig. 1a, the backscattered electron images revealed uniform distribution of the ferrite (dark areas) and the relaxor (light areas) in the sample. The ceramic is dense and fine grained with grain sizes $0.5-3 \mu \mathrm{m}$ for the relaxor and below $0.5-1 \mu \mathrm{m}$ for the ferrite (Fig. 1a,b).
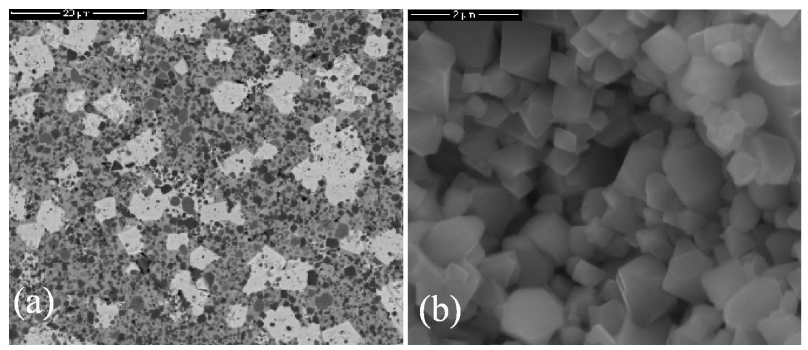

Fig. 1. Micrographs of a fractured cross-section of $\quad 0.5 \mathrm{CoFe}_{2} \mathrm{O}_{4}-0.375 \mathrm{~Pb}\left(\mathrm{Fe}_{2 / 3} \mathrm{~W}_{1 / 3}\right) \mathrm{O}_{3}-0.125 \mathrm{PbTiO}_{3}$ composite: (a) back scattered electron image, (b) secondary electron image.

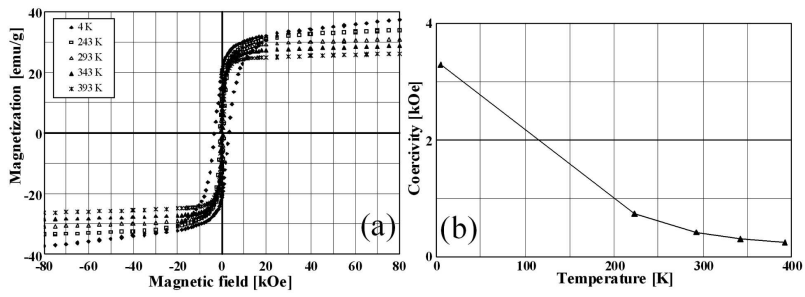

Fig. 2. (a) Magnetic hysteresis, (b) coercivity versus temperature for bulk $0.5 \mathrm{CoFe}_{2} \mathrm{O}_{4}$ $0.375 \mathrm{~Pb}\left(\mathrm{Fe}_{2 / 3} \mathrm{~W}_{1 / 3}\right) \mathrm{O}_{3}-0.125 \mathrm{PbTiO}_{3}$ composite in the temperature range $4-393 \mathrm{~K}$.

The hysteresis curves shown in Fig. 2a are typical of hard magnetic materials. The coercivities decrease with increasing temperature from $3.29 \mathrm{kOe}$ at $4 \mathrm{~K}$ to $0.24 \mathrm{kOe}$ at $393 \mathrm{~K}$ (Fig. 2b).

The magnetization at high magnetic field which is not completely saturated implies antiferomagnetic ordering existing in the sample. The magnetization at an applied magnetic field of $80 \mathrm{kOe}$ decreases with increasing temperature from $35.0 \mathrm{emu} / \mathrm{g}$ at $4 \mathrm{~K}$ to $26.2 \mathrm{emu} / \mathrm{g}$ at $393 \mathrm{~K}$. Because of a two-phase ferromagnetic-ferroelectric composition, the maximal magnetization values for the investigated composites are about twice lower than those for $\mathrm{CoFe}_{2} \mathrm{O}_{4}$ ferrite $(66-83 \mathrm{emu} / \mathrm{g}[6,7])$.

In Fig. 3a, the temperature dependence of magnetization is presented for various dc magnetic fields in the range 1-80 kOe. For strong magnetic fields higher than $30 \mathrm{kOe}$, the magnetization decreases with temperature

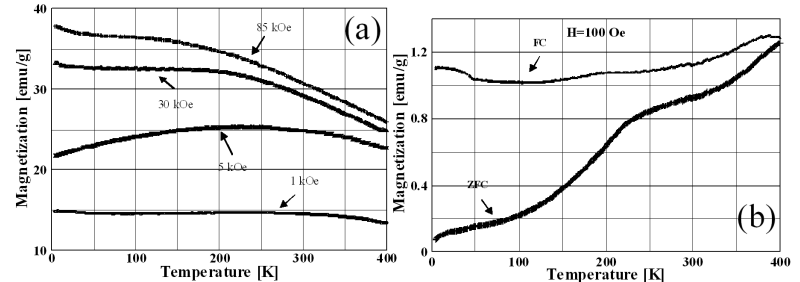

Fig. 3. (a) Magnetizations measured at different magnetic fields of 1-80 kOe, (b) ZFC and FC magnetizations at magnetic field of $100 \mathrm{Oe}$ for $0.5 \mathrm{CoFe}_{2} \mathrm{O}_{4}$ $0.375 \mathrm{~Pb}\left(\mathrm{Fe}_{2 / 3} \mathrm{~W}_{1 / 3}\right) \mathrm{O}_{3}-0.125 \mathrm{PbTiO}_{3}$ composite in the temperature range $4-393 \mathrm{~K}$.

rise in the whole range. For lower magnetic fields comparable with coercivities $(1-5 \mathrm{kOe})$, the magnetization initially grows with increasing temperature due to decreasing coercivity, and then starts to diminish as a result of enhanced thermal movements of magnetic moments.

Figure 3b shows the zero-field cooled (ZFC) and field cooled (FC) magnetizations at a weak magnetic field of 100 Oe for CF-PFW-PT composite in the temperature range 4-393 K. A large bifurcation of these curves implies spin glass behavior related to $\mathrm{CoFe}_{2} \mathrm{O}_{4}$ ferrite. An anomaly observed in $\mathrm{FC}$ curve corresponding to a rapid decrease in the magnetization in the temperature range $4-50 \mathrm{~K}$, could be attributed to the antiferromagnetic ordering of the PFW relaxor phase.
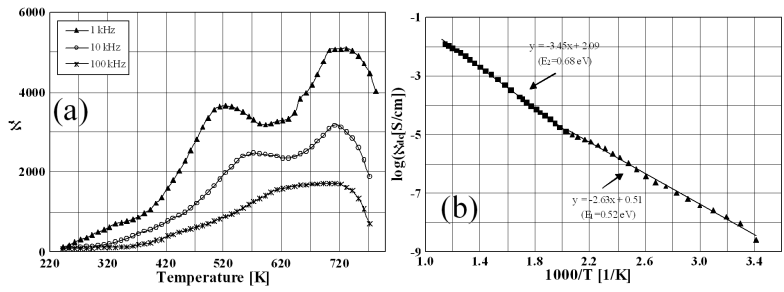

Fig. 4. (a) Temperature dependence of the real part of dielectric permittivity at $1 \mathrm{kHz}, 10 \mathrm{kHz}$ and $100 \mathrm{kHz}$, (b) dc electrical conductivity versus reciprocal temperature for $0.5 \mathrm{CoFe}_{2} \mathrm{O}_{4}-0.375 \mathrm{~Pb}\left(\mathrm{Fe}_{2 / 3} \mathrm{~W}_{1 / 3}\right) \mathrm{O}_{3}-$ $0.125 \mathrm{PbTiO}_{3}$ composite.

In Fig. 4a the real part of dielectric permittivity of the composite at $1 \mathrm{kHz}, 10 \mathrm{kHz}$ and $100 \mathrm{kHz}$ is depicted as a function of temperature ranging from 218 to $773 \mathrm{~K}$.

In the $\varepsilon^{\prime}=f(T)$ curves, there are flat and low humps near $320 \mathrm{~K}$ related presumably to the suppressed relaxor diffuse transition, and broad and high maxima at the level of 1700-5000 attributed to dielectric relaxation of the relaxor and the ferrite phases. As frequency increases, the humps and maxima decrease and shift towards higher temperatures, and overlapping of two relaxation peaks occurs.

Figure 4b displays the dc electrical conductivity of $\mathrm{CF}-$ PFW-PT ceramic versus reciprocal temperature. The activation energies determined from the linear parts of 
the Arrhenius plot are $0.52-0.68 \mathrm{eV}$ in the investigated temperature range $293-873 \mathrm{~K}$.

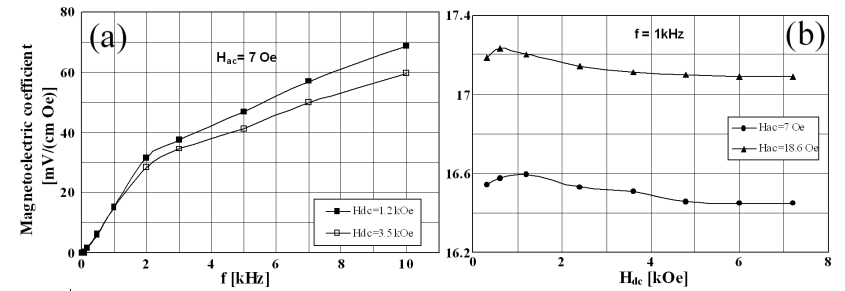

Fig. 5. Magnetoelectric coefficient of $0.5 \mathrm{CoFe}_{2} \mathrm{O}_{4}-$ $0.375 \mathrm{~Pb}\left(\mathrm{Fe}_{2 / 3} \mathrm{~W}_{1 / 3}\right) \mathrm{O}_{3}-0.125 \mathrm{PbTiO}_{3}$ composite at room temperature (a) as a function of frequency of ac magnetic field at dc magnetic field of 1.2 and $3.5 \mathrm{kOe},(\mathrm{b})$ as a function of dc magnetic field at ac magnetic field of 7 and 18.6 Oe and at ac magnetic field frequency of $1 \mathrm{kHz}$.

The obtained $0.5 \mathrm{CoFe}_{2} \mathrm{O}_{4}-0.375 \mathrm{~Pb}\left(\mathrm{Fe}_{2 / 3} \mathrm{~W}_{1 / 3}\right) \mathrm{O}_{3}-$ $0.125 \mathrm{PbTiO}_{3}$ composite exhibits distinct magnetoelectric effect at room temperature. In Fig. 5a and b the magnetoelectric voltage coefficient is plotted as a function of ac magnetic field frequency and dc magnetic field intensity, respectively. The magnetoelectric coefficient increases with increasing frequency of ac field, attaining a value of $70 \mathrm{mV} /(\mathrm{cm} \mathrm{Oe}$ ) at $10 \mathrm{kHz}$ (Fig. 5a). As shown in Fig. $5 \mathrm{~b}$ for the range $0.3-7.2 \mathrm{kOe}$, the magnetoelectric coefficient reaches a flat maximum at $0.6-1.2 \mathrm{kOe}$, and then slightly decreases with increasing dc magnetic field. The influence of ac magnetic field intensity is ambiguous, probably due to the effect of sample history.

\section{Conclusions}

The prepared multiferroic $0.5 \mathrm{CoFe}_{2} \mathrm{O}_{4}$ $0.375 \mathrm{~Pb}\left(\mathrm{Fe}_{2 / 3} \mathrm{~W}_{1 / 3}\right) \mathrm{O}_{3}-0.125 \mathrm{PbTiO}_{3}$ composite exhibits high dielectric permittivity, hard magnetic properties and high magnetoelectric voltage coefficient at room temperature. Owing to low sintering temperature, this material is suitable for thick film technology and LTCC applications.

\section{Acknowledgments}

The authors thank Prof. J. Pszczoła from AGH University of Science and Technology, Faculty of Applied Physics, for his kind support and the fruitful discussion of the results of magnetoelectric measurements.

The work has been financed by the Polish National Centre for Research and Development under the Eureka project E!4570-IPCTECH.

\section{References}

[1] G. Srinivasan, R. Hayes, C.P. Devreugd, V.M. Laletsin, N. Paddubnaya, Appl. Phys. A 80, 891 (2005).

[2] S. Yu, H. Huang, L. Zhou, Y. Ye, S. Ke, Ceram. Int. 34, 701 (2008).

[3] R. Grossinger, G.V. Duong, R. Sato-Turtelli, J. Magn. Magn. Mater. 320, 1972 (2008).

[4] V. Corral-Flores, D. Bueno-Baqués, R.F. Ziolo, Acta Mater. 58, 764 (2010).

[5] L. Yan, Y. Yang, Z. Wang, Z. Xing, J. Li, D. Viehland, J. Mater. Sci. 44, 5080 (2009).

[6] O. Caltun, I. Dumitru, M. Feder, N, Lupu, H. Chiriac, J. Magn. Magn. Mater. 320, e869 (2008).

[7] G. Concas, G. Spano, C. Cannas, A. Musinu, D. Peddis, G. Piccaluga, J. Magn. Magn. Mater. 321, 1893 (2009).

[8] L. Feng, H. Guo, Z.G. Ye, J. Mater. Res. 22, 2116 (2007).

[9] S.A Ivanov, S.G Eriksson, R. Tellgren, H. Rundlof, Mater. Res. Bull. 39, 2317 (2004).

[10] A. Kumar, G.L. Sharma, R.S. Katiyar, R. Pirc, R. Blinc, J.F. Scott, J. Phys., Condens. Matter 21, 382204 (2009). 